\title{
KONSEP IHSAN `IZZ AL-DIN IBN ABD AL-SALAM
}

\author{
Zulkayandri
}

\begin{abstract}
There are many passages in the Qur'an that oblige ihsân (doing goodness). The ulamas understand differently the term of ihsân. The meanings of the term that ulamas mentioned among other are: patient in conducting well worship, doing all order of Allah, giving the rights of relatives, and doing totally good deeds. Izz al-Qur'an-Din ibn Abd al-Qur'an-Salam comprehends ihsân as keeping all kinds of use or benefit and preventing all forms of destruction pertaining with human being, flora, fauna, and environment in term of worshiping to Allah in realization of goodness and harmony among the creature.
\end{abstract}

Key words: iḥsân (doing goodness), mashlahah (use), and Islamic law.

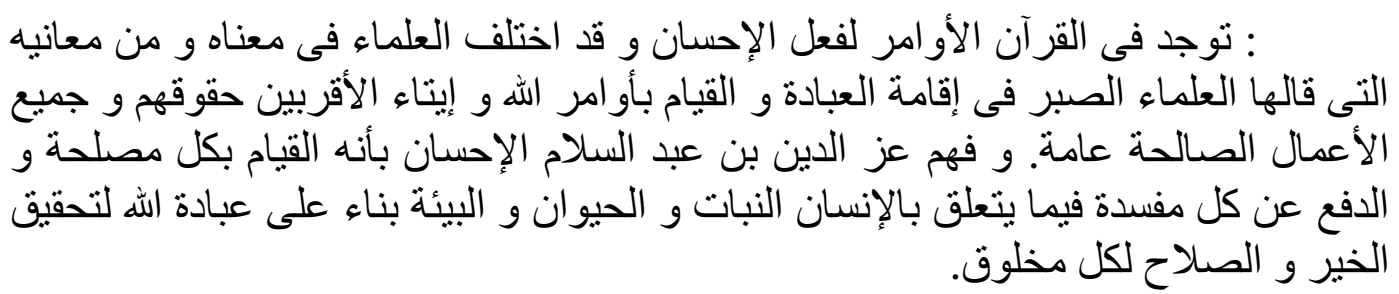

\section{Pendahuluan}

Ulama ushul sepakat bahwa hukum-hukum syara' mengandung kemaslahatan bagi manusia dan hukum-hukum syara' itu diturunkan Syari' untuk memelihara tujuan-tujuannya pada makhluk ${ }^{1}$. Oleh sebab itu tujuan ditetapkannya hukum-hukum syara' adalah untuk memelihara kemaslahatan manusia, bahkan Allah mengutus para Rasul dan menurunkan kitab-kitab suci untuk menegakkan kemaslahatan dan mencegah serta menghilangkan kemafsadatan dari manusia di dunia dan di akhirat ${ }^{2}$.

Maslahat adalah lazzah (kelezatan) atau farh (kegembiraan) dan hal-hal yang menyebabkannya. Sedangkan mafsadah adalah 'alam (penderitaan) atau ghamm (kesedihan) dan penyebab-penyebabnya. Syara' tidak membedakan antara yang masih terselubung dengan yang sudah jelas, sedikit atau banyak, walau sebesar biji sawi, biji kurma atau biji gandum. Maka barang siapa yang melakukan kebaikan atau kejahatan, sekecil apapun, pasti akan melihat akibatnya ${ }^{3}$. Dalam al-Qur`an Allah SWT berfirman:

فمن يعمل مثقال ذرة خير ا بره, وهن يعمل مثقال ذرة شر ا بره (الزلزلة: 7-8) Artinya:

"Barangsiapa yang mengerjakan kebaikan seberat zarrahpun, niscaya dia akan melihat (balasan) nya. Dan barangsiapa yang mengerjakan kejahatan seberat zarrahpun, niscaya dia akan melihat (balasan) nya pula (al-Zalzalah: 8)".

Jika ada perbuatan baik yang kecil nilainya tentu ada pula yang lebih tinggi dan seterusnya, demikian juga perbuatan jahat, jika ada yang kecil tentu ada 
yang besar dan ada pula yang sangat besar. Sejalan dengan ini, ulama ujul sepakat, bahwa khitab Allah yang berkenaan dengan perbuatan mukallaf, yang disebut dengan al-hukm al-taklif terdiri dari lima tingkatan, yaitu: al-wuj-b, al-nadb, al-ibahah, al-karahah, dan al-tahrim ${ }^{4}$.

Kemudian Allah mewajibkan perbuatan ihsan terhadap segala sesuatu untuk selama-lamanya dengan firmanNya:

\section{Artinya:}

$$
\text { إن الله يأمر بالعدل و الإحسان ...(النحل: 90) }
$$

"Sesungguhnya Allah menyuruh (kamu) berlaku adil dan berbuat ihsan..." (al-Nahal: 90).

Perbuatan Ihsan dalam ayat di atas dapat difahami sebagai bentuk perintah kepada mukmin agar melaksanakan kebaikan dan menolak segala bentuk kemafsadatan, hal ini selaras dengan misi yang dibawa Nabi Muhammad SAW sebagai rahmat bagi sekalian alam. Allah menegaskan:

\section{Artinya:}

$$
\text { وما أرسلناك إلا رحمة للعالمين (الأنبياء: 107) }
$$

“Dan tiadalah Kami mengutus kamu, melainkan untuk (menjadi) rahmat bagi semesta alam" (al-Anbiya': 107).

Menjadi rahmat bagi sekalian alam berarti, kehadiran nabi S.A.W. di muka bumi sebagai utusan Allah berfungsi untuk mewujudkan kemaslahatan seluruh makhluk yang ada di alam ini. Fungsi ini direalisir dengan melaksanakan petunjuk-petunjuk wahyu yang diturunkan Allah. Hukumhukum syara' adalah sebagian dari kandungan wahyu Allah, oleh sebab itu menerapkan hukum-hukum syara' dalam seluruh aspek kehidupan merupakan bentuk realisasi kemaslahatan bagi manusia dan makhluk lainnya yang ada di alam, sekaligus menjadi salah satu misi kenabian yang dibawa Rasulullah S.A.W.

Karena penting dan tingginya nilai perbuatan ihsan itu Allah memberi motivasi dengan firmanNya:

Artinya:

$$
\text { و أحسنو ا إن الله يحب المحسنين (البقرة : 195) }
$$

“...dan berbuat baiklah, karena sesungguhnya Allah menyukai orangorang yang berbuat baik..." (al-Baqarah: 195).

Jika Allah telah menyatakan kecintaanNya terhadap orang yang melakukan perbuatan Isan, maka selayaknya orang-orang yang beriman kepada Allah menyambut pernyataan ini dengan antusias yang tinggi, dengan memelihara segala tindak-tanduknya agar senantiasa termasuk dalam kategori perbuatan Ihsan. Dengan demikian sangat diperlukan suatu penjelasan tentang perbuatan Ihsan yang dimaksud oleh Syari' tersebut.

\section{Pengertian Ihsan}


Secara etimologi kata Ihsan (إحْنَان) merupakan bentuk majdar dari

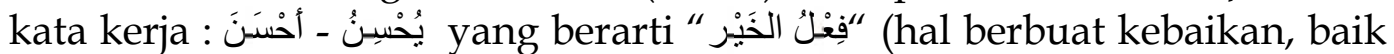
terhadap diri sendiri maupun terhadap yang lainnya) dan merupakan lawan kata أسَاءَ. 5 .

Dalam al-Qur`an kata Ihsan (إحسان) dan yang seakar dengannya muncul sebanyak 195 kali dalam berbagai surat dan ayat. Sedangkan khusus kata ihsan (إحسان) disebutkan pada dua belas tempat ${ }^{6}$.

Menurut 'Izz al-Din berdasarkan petunjuk al-Qur'an surat al-Nahal:90 difahami, bahwa Allah mewajibkan perbuatan ihsan terhadap segala sesuatu terus-menerus untuk selama-lamanya ${ }^{7}$, kemudian Allah menyatakan bahwa Ia mencintai orang-orang yang senantiasa berbuat ihsan (QS; 2:195)

Menurut 'Izz al-Din perintah Allah untuk berbuat ihsan tersebut menjadi sebab untuk memperoleh cinta Allah, maka selayaknya setiap muslim menyambut seruan ini dengan motivasi tinggi dan menerapkan perbuatan ihsan bukan hanya terhadap manusia saja, tetapi juga terhadap makhluk Allah yang lain seperti: Malaikat, tumbuh-tumbuhan, binatang dan lainya ${ }^{8}$.

Perbuatan al-ihsan dalam pandangan 'Izz al-Din terhimpun dibawah kaidah:

Artinya:

$$
\text { جلب المصالح و درء المفاسد9 }
$$

“Mengambil ( menegakkan ) segala bentuk kemaslahatan dan menolak (mencegah) segala bentuk mafsadah"

Kemudian ditempat lain 'Izz al-Din menyatakan :

Artinya:

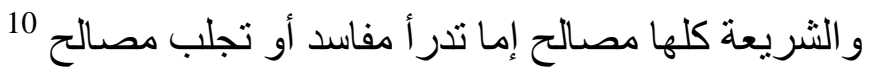

“...dan syari'at itu seluruhnya kemaslahatan, baik menolak kemafsadatan, maupun menegakkan kemaslahatan,"

Dengan demikian ihsan yang dimaksud oleh 'Izz al-Din disini adalah kemaslahatan, dan kemaslahatan itu merupakan tujuan diturunkannya hukum syara' kepada manusia, baik dalam bentuk perintah menegakkan kemaslahatan, maupun berbentuk perintah untuk mencegah suatu kemafsadatan. Kemudian menegakkan segala bentuk kemaslahatan dan menolak segala bentuk mafsadah berlaku dalam segala aspek kehidupan, bukan saja memelihara hal-hal yang berhubungan dengan manusia, berupa memelihara agama, akal, jiwa, keturunan dan harta. Tetapi juga terhadap mahluk Allah yang lain, seperti: Malaikat, fauna, flora, dan lingkungan hidup seluruhnya.

Menurut 'Izz al-Din ihsan memiliki wasil, kemudian wasil tersebut memiliki ahkam al-maqjid yang berbentuk wajib, haram, mandib, makruh dan mubahi1. Tingkatan-tingkatan hukum ini menjadi sarana-sarana yang dibentuk dalam kerangka mewujudkan atau menghantarkan terealisasinya ihsan dalam kehidupan sebagai tujuan-tujuan (maqjid) ditetapkannya hukum syara', oleh sebab itu hukum-hukum itu disebut "ahkam al-maqjid". Sementara wasil itu sendiri adalah segala bentuk perbuatan yang dapat dijadikan mediator untuk mencapai ihsan atau tercapainya kemaslahatan dan terhindar dari kemudaratan dalam kehidupan di dunia dan akhirat. 
Untuk mencermati cara pandang 'Izz al-Din ini penulis mengemukakan pendapat beberapa ulama mengenai pengertian perintah Ihsan dalam surat alNahal 90. Al-'abari berkomentar tentang pengertian al- Ihsan dalam ayat ini dengan mengutip pendapat Ibn Abbas:

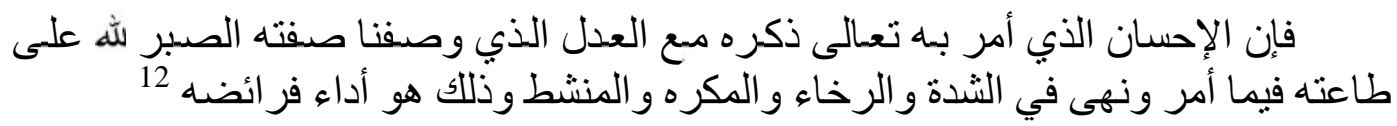

Artinya:

"Sesungguhnya al- Ihsan yang diperintahkan Allah Ta'ala bersama al-'adl (dalam ayat ini) adalah yang kami sebut sifatnya berupa sabar karena Allah dalam melaksanakan perintah dan laranganNya, baik dalam keadaan susah maupun senang, berupa melaksanakan ketetapan-ketetapanNya".

Dalam tafsir Jalalain dijelaskan, bahwa kata al- Ihsan dalam ayat ini dapat berarti:

$$
\text { .... الإحسان أداء الفر ائض أو أن تعبد الله كأنك تر اه كما في الحديث } 13
$$

Artinya:

“...dan pengertian al- Ihsan dapat berupa melaksanakan ketetapanketetapan (Allah) atau beribadah kepada Allah seakan-akan engkau melihatNya" sebagaimana termuat dalam hadis:

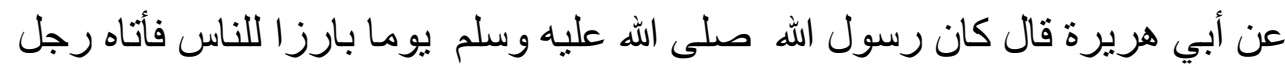

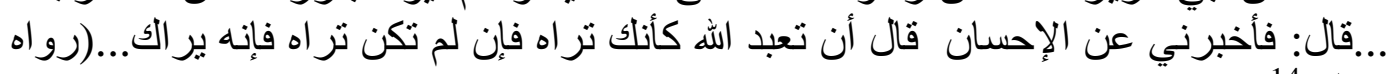

Artinya:

Dari Abi Hurairah R.A. berkata: "Pada suatu hari Rasulullah S.A.W. keluar menjumpai manusia, tiba-tiba datang seorang laki-laki (Malaikat Jibril)... seraya bertanya: Jelaskanlah kepadaku tentang al- Ihsan?, Nabi menjawab: Hendaklah engkau beribadah kepada Allah seolah-olah engkau melihatnya, jika engkau belum mampu demikian, maka ketahuilah sesungguhnya Ia melihatmu..." (HR. Muslim).

Dalam tafsir al-Durr al-Manar, Al-Suyi menjelaskan:

$$
\begin{aligned}
& \text { ئ.... الإحسان : أداء الفرائض وإيتاء ذي القربى, قال: إعطاء ذوي الرحم الحق الذي }
\end{aligned}
$$

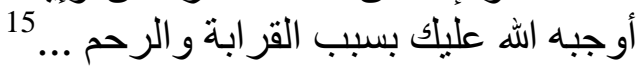

Artinya:

"...dan al- Ihsan dalam ayat ini adalah melaksanakan ketetapan-ketetapan (Allah) dan memberi (kebutuhan) kaum-kerabat, kemudia ia berkomentar: memberi kerabat yang memiliki hubungan (tali darah) adalah hak yang diwajibkan Allah untuk ditunaikan disebabkan adanya kekerabatan dan pertalian darah..."

Al-Baidawi menyatakan: 


$$
\begin{aligned}
& \text { و الإحسان إحسان الطاعات و هو: إما بحسب الكمية كالتطوع بالنو افل أو بحسب الكيفية }
\end{aligned}
$$

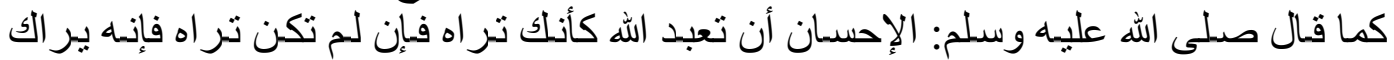

$$
\begin{aligned}
& \text { و إيتاء ذي القربى و إعطاء الأقارب ما يحتاجون إليه اليه } 16
\end{aligned}
$$

Artinya:

" Ihsan yang dimaksud dalam ayat ini adalah ihsanu al-kamilah, baik berdasarkan kuantitasnya, seperti melakukan ibadah sunat dengan shalat sunat. Atau berdasarkan kualitasnya, sebagaimana sabda SAW: al-ihsan adalah hendaklah engkau menyembah Allah seakan-akan melihatnya, jika tidak mampu, maka sesungguhnya Dia melihatmu. Kemudian memberikan (sedekah) kepada kaum-kerabat apa yang mereka perlukan".

Dari penjelasan empat kitab tafsir di atas, dapat ditemukan dua pengertian al- Ihsan dalam ayat al-Nahal 90. Pertama, pengertian yang diantaranya mengindikasikan pelaksanaan hukum syara', yaitu melaksanakan ketentuanketentuan Allah yang diaplikasikan dengan hukum fardhu, wajib, sunat, makruh, haram dan mubah sebagai bentuk-bentuk hukum syara'. Sedangkan pengertian kedua lebih menggambarkan situasi spritualitas mukallaf ketika melaksanakan hukum syara', karena kesadaran spritual yang mampu melihat existensi Allah yang senantiasa dapat memantau semua prilaku hambaNya secara lahir dan batin akan melahirkan rasa ikhlas melakukan ibadah dan takut berbuat dosa atau melanggar ketentuan Allah kapanpun dan dimanapun.

Berdasarkan uraian di atas penulis merumuskan bahwa pengertian al-Ihsan menurut terminologi yang digunakan dalam tulisan ini adalah menegakkan segala bentuk kemaslahatan dan mencegah segala bentuk kemafsadatan yang berhubungan dengan manusia, flora, fauna, lingkungan hidup dan sebagainya dengan menerapkan hukum wajib, sunat, makruh, haram dan mubah dalam kerangka pengabdian kepada Allah untuk mewujudkan kebaikan dan keserasian bagi seluruh mahluk, lebih spesifik, bagi manusia bertujuan untuk memperoleh kemaslahatan dan terhindar dari mafsadah di dunia atau di akhirat atau keduanya sekaligus.

Bentuk-bentuk Aplikasi Ihsan

Ditinjau dari target operasionalnya menurut 'Izz al-Din konsep Ihsan yang diaplikasikan dengan kaidah jalb al-mashalih wa dar al-mafasid terdiri dari tiga bentuk ${ }^{17}$ :

Pertama, Ihsan al-'ibadat sebagai orientasi wara' yang tertinggi, yaitu: "hendaklah engkau beribadah kepada Tuhanmu seolah-olah kamu melihatnya, jika tidak mampu, maka bersikaplah seakan Ia melihatmu". Sebagaimana dijelaskan Rasulullah dalam sabdaNya:

$$
\begin{aligned}
& \text { عن أبي هريرة قال كان رسول الله صلى الله عليه وسلم يوما بارزا للناس فأتاه رجل فئل }
\end{aligned}
$$

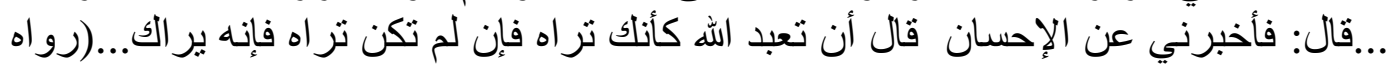

$$
\begin{aligned}
& \text { مسلم) }
\end{aligned}
$$

Artinya:

Dari Abi Hurairah R.A. berkata: pada suatu hari Rasulullah S.A.W. keluar menjumpai manusia, tiba-tiba datang seorang laki-laki (Malaikat Jibril)... seraya bertanya: "Jelaskanlah kepadaku tentang al-ihsan?" Nabi 
menjawab: "Hendaklah engkau beribadah kepada Allah seolah-olah engkau melihatnya, jika engkau belum mampu demikian, maka ketahuilah sesungguhnya Ia melihatmu..." (HR. Muslim).

Menurut 'Izz al-Din sikap yang terbaik adalah jika seorang mukmin mampu beribadah seraya memandang Allah", karena jika ia mampu seakanakan melihat Allah dalam beribadah, maka ia akan memuliakan dan mengagungkanNya setinggi-tingginya, ia akan malu dari Allah dan akan menyempurnakan ibadahnya ${ }^{19}$.

Kedua, Ihsan ila al-khalaiq ( ihsan terhadap seluruh mahluk ). Menurut 'Izz al-Din Ihsan bentuk ini diterapkan dengan cara mengambil manfaat dan mencegah mudarat atau keduanya sekaligus, tanpa membedakan sedikitbanyaknya, mulia atau hinanya. ${ }^{20}$ Karena setiap perbuatan akan mendapat balasan yang setimpal, sebagaimana firman Allah:

$$
\text { فمن يعمل مثقال ذرة خير ا يره, ومن يعمل منقال ذرة شر ا يره (الزلزلة:7-7) }
$$

Artinya:

“Barangsiapa yang mengerjakan kebaikan seberat zarrahpun, niscaya dia akan melihat (balasan) nya. Dan barangsiapa yang mengerjakan kejahatan seberat zarrahpun, niscaya dia akan melihat (balasan) nya pula". (alZalzalah: 8-7)

Perbuatan sekecil apapun akan dipertanggung jawabkan dihadapan Allah, setiap kebaikan merupakan sedekah, walaupun hanya mencerahkan muka kepada orang lain, Nabi SAW. Bersabda:

$$
\text { البخارى ومسلم) ابنى شيبة: عن النبي صلى الله عليه وسلم قال: كل معروف صدقة (رواه }
$$

\section{Artinya:}

Ibn Abu Syaibah berkata: dari Nabi SAW bersabda: "Setiap kebaikan itu adalah sedekah". (HR. Bukhari dan Muslim).

Sebaliknya tidak dibenarkan menyakiti orang lain, bahkan terhadap malaikat sekalipun, karena menurut 'Izz al-Din mereka dapat tersakiti oleh sikap manusia22, demikian juga terhadap binatang ketika menyembelihnya, satu sembelihan lebih utama dari beberapa kali, karena berulang kalinya sayatan lebih menyakiti binatang sembelihan itu, sabda Nabi:

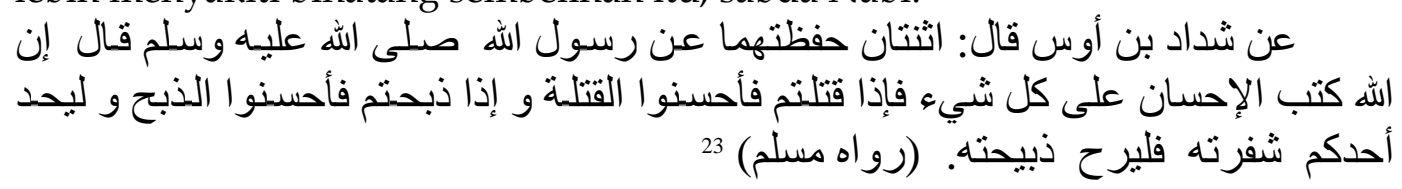

Artinya:

Syaddad bin `Aus berkata: "Dua hal yang kuhafal dari Rasulallah SAW.” yaitu: "Sesungguhnya Allah mewajibkan berbuat ihsan terhadap segala sesuatu, apabila engkau membunuh, maka gunakanlah cara yang baik, dan jika engkau menyembelih, maka hendaklah kamu menajamkan mata pisaunya agar meringankan (rasa sakit) pada binatang sembelihannya". (HR. Muslim)

Ketiga, ihsan al-mar' ila nafsih (ihsan terhadap diri sendiri). Dilakukan dengan cara senantiasa berbuat kemaslahatan dan melaksanakan segala perintah 
Allah yang bersifat wajib, sunnah, dan mubah. Kemudian menghindari mafsadah yang terdapat dalam larangan Allah yang bersifat makruh dan haram, tanpa membedakan sedikit-banyak dan tinggi-rendahnya, karena setiap perbuatan baik dan buruk sekecil apapun akan mendapat ganjaran, setiap perbuatan zalim terhadap diri sendiri akan merasakan akibatnya yang merugikan pelaku itu sendiri, sebagaimana Allah berfirman:

$$
\text { من عمل صالحا فلنفسه ومن أساء فعليها وما ربك بظلام للعبيد (فصلت: 46) }
$$

Artinya:

“Barangsiapa yang mengerjakan amal yang saleh maka (pahalanya) untuk dirinya sendiri dan barangsiapa yang berbuat jahat maka (dosanya) atas dirinya sendiri; dan sekali-kali tidaklah Tuhanmu menganiaya hambahamba (Nya)" (Fusilat: 46).

Dalam kaitannya dengan bahasan ini, menurut Muhammad AbZahrah, ${ }^{24}$ Islam diciptakan untuk membentuk tatanan masyarakat idaman $\left(f a^{\prime} i l\right)$, memiliki dan membangun cinta-kasih serta keadilan dari tiga sisi:

Pertama, membentuk individu-individu agar menjadi sumber kebaikan bagi komunitasnya dengan cara menyari'atkan ibadah kepada Allah untuk mendidik jiwa, kemudian menguatkan hubungan horizontal sesama mukmin dan selainnya dengan melarang perbuatan hasad, dengki, zalim dan keji. Itulah sebabnya Allah memfardhukan jalat agar terhindar dari perbuatan keji dan Mungkar, mewajibkan zakat agar memperhatikan kesusahan orang disekitarnya dan membangun hubungan baik antara miskin dan kaya.

Kedua, Menegakkan keadilan ditengah masyarakat, baik diantara sesama mukmin, maupun dengan anggata masyarakat non muslim lainnya. Keadilan dalam Islam merupakan tujuan yang paling utama, yang meliputi berbagai dimensi, berupa keadilan dalam penerapan, keadilan dalam peradilan dan kesaksian.

Ketiga, dari sisi substansi, Islam bertujuan menegakkan kemaslahatan dan menolak kemafsadatan. Substansi ini terkandung didalam seluruh aspek Islam, maka setiap yang ditetapkan oleh al-Qur`an dan al-Hadis didalam terdapat maslahah yang sebenarnya, walaupun secara zahir, ada yang tidak sesuasi dengan keinginan hawa nafsu manusia.

\section{Maslahat Hakiki dan Majazi}

Menurut 'Izz al-Din ekpresi syara' tentang maslahah dan mafsadah seringkali menggunakan istilah-istilah yang bermacam-macam, seperti: almahabbah (disukai), al-makruh (dibenci), al-lasanat (kebaikan), al-sayyiat (kejelekan), al-'urf (dikenal), al-nakar (asing), al-khair (kebaikan), al-Syar (keburukan), al-nafa' (manfaat), al-khar (bahaya), al-hasan (baik), al-qublu (jelek)25.

Ungkapan-ungkapan maslahah dan mafsadah ini memiliki korelasi yang erat dengan metode penalaran dalam menggali hukum syara' dari naj-na; syari'ah, karena ungkapan-ungkapan tersebut diangkat dari naj-na syara' itu sendiri. Setiap perbuatan yang di perintahkan oleh Syari', atau khabar yang mengindikasikan perintahnya, atau Ia puji perbuatan itu, atau Ia puji orang yang melakukan perbuatan itu, atau Ia jadikan perbuatan itu sebagai sebab kebaikan 
dunia atau akhirat, maka bentuk-bentuk ini mengindikasikan, bahwa perbuatan tersebut diperintah oleh Syari'.

Sebaliknya, semua perbuatan yang dilarang oleh Syari', atau khabar yang mengindikasikan adanya larangan itu, atau suatu perbuatan dicela oleh Syari', atau Ia cela pelakunya, atau Ia nyatakan perbuatan itu menyebabkan terjadinya keburukan dunia atau akhirat, maka bentuk-bentuk ungkapan ini menunjukkan bahwa perbuatan itu dilarang.

Sedangkan setiap perbuatan yang diberikan kebebasan oleh syari' untuk memilih untuk melakukan atau tidak dengan kesamaan dimensi maslahah dan mafsadahnya, atau Ia beritahu tentang kesamaannya, maka semua ini mengindikasikan, bahwa perbuatan tersebut adalah mubah.

Maslahat dan mafsadat yang haqiqi adalah yang termuat dalam na; atau yang sesuai dengan petunjuk-petunjuk naj. Tidaklah layak mengungkapkan kesukaran-kesukaran yang ditemui dalam melaksanakan ibadah dengan ungkapan yang mengindikasi mafsadat, sebaliknya kurang tepat menurut moral, jika kelezatan-kelezatan yang dirasakan ketika berbuat dosa diungkapkan dengan simbol-simbol kemaslahatan ${ }^{26}$, meskipun hadis menyatakan:

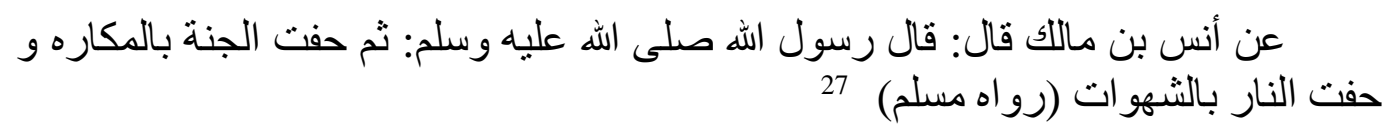

Artinya:

Dari Anas bin Malik berkata: Rasulullah S.A.W. bersabda: "Surga dikelilingi oleh hal-hal yang tidak menyenangkan, dan neraka dikitari oleh kesenangan-kesenangan syahwat". (HR. Muslim).

"Tidak menyenangkan dan menyenangkan" dalam hadis ini diukur berdasarkan ukuran hawa nafsu, hal ini diindikasikan oleh kata syahwat diujung hadis. Sedangkan hukum syara' di tegakkan untuk membangun kemuliaan akhlaq dan menegakkan keadilan, maka kemuliaan dan keadilan yang sebenarnya hanya terdapat pada sumbernya, yakni petunjuk-petunjuk Allah SWT yang diturunkan melalui Rasulullah SAW.

\section{Kesimpulan.}

Konsep ihsan yang dimaksud 'Izz al-Din adalah menegakkan segala bentuk kemaslahatan dan mencegah segala bentuk kemafsadatan yang berhubungan dengan manusia, flora, fauna, lingkungan hidup dan sebagainya dalam kerangka pengabdian kepada Allah untuk mewujudkan kebaikan dan keserasian bagi seluruh mahluk, lebih spesifik, bagi manusia bertujuan untuk memperoleh kemaslahatan dan terhindar dari mafsadah di dunia atau di akhirat atau keduanya.

\section{Catatan Akhir:}

1 Ibrahim bin Musa al-Lukhmi Ab- Ishaq al-Syatibi (selanjutnya disebut al-Syatibi), alMuwafaqat fi Usul al-Syari'ah, (Beirut: Daar al-Ma'rifah, tth), juz II, h. 6. 
Al-Fikra: Jurnal Ilmiah Keislaman, Vol. 4, No. 1, Januari-Juni 2005

2 Sultan al-Ulama 'Izz al-Din Abd al-'Aziz bin 'Abd al-Salam al-Silmi (selanjutnya disebut 'Izz al-Din saja), al-Qawa'id al-Kubra, (Damaskus: Dar al-Fikr, 1416 H), h. 32.

${ }^{3}$ Ibid.

4 Jalal al-Din 'Abd al-Rahman, Gayat al-Wushul ila Daqa iq ilm al-'Ushl, (ttp: Maba'at alSa'adah, 1979), juz I, h. 137-142.

5 Muhammad bin Makram Ibn Manzhur al-Afriqi al-Mishri, Lisan al-'Arab, (Beirut: Dar Shadir, tth), cet. I, juz XIII, h. 1.

${ }^{6}$ Muhammad Fu`ad al-Baqi, al-Mu'jam al-Mufahras li al-Faz al-Qur`an al-Karim, (Kairo: Dar alHadi $_{i}, 1991$ M), cet. III, h. 256-260.

${ }^{7}$ Izz al-Din, al-Qawa'id al-Kubra, (Damaskus: Dar al-Fikr, 1416 H), h. 33.

8 Ibid.

9 Ibid., h. 34.

10 ‘Izz al-Din, al-Qawa'id al-Kubra, (ttp: Dar al-Jil, 1980 M. / 1400 H.), juz I, h. 11.

11 Ibid. h. 43.

12 Muhammad bin Jarir bin Yazid bin Khalid al-Thabari Abd. Ja'far (selanjutnya disebut alThabari), Jami' al-Bayan 'an Takwiil al-Qur'an, (Beirut: Dar al-Fikr, 1405 H), juz XIV, h. 163. Bandingkan dengan Abi zahir Ya'qub al-Fair-z Abadi, Tanwir al-Miqbas min Tafsir Ibn 'Abbas, (Beirut: Dar al-Fikr, 1995), h. 277.

${ }^{13}$ Muhammad bin Ahmad Abd al-Rahman bin Abi Bakr al-Mahalli dan Abd al-Rahman Ibn kamal Jalal al-Din al-Suy fi, Tafsir al-Jalalain, (Kairo: Dar al-Hadis, tth), juz I, h. 359.

14 Muslim bin al-Hajjaj Abd al-Husain al-Qusyairi al-Naisaburi (selanjutnya disebut Imam Muslim), Shahih Muslim, (Beirut: Dar al-Ihya' al-Turas al-'Arabi, tth), juz I, h. 39. Lihat juga Muhammad bin Isma'il Ab- Abdillah al-Bukhari (selanjutnya disebut Imam Bukhari), al-Jami' alKabir, (Beirut: Dar Ibn Kasir, 1987M/1407H), juz I, h. 27.

15 Abd al-Rahman bin Kamal Jalal al-Din al-Suyabi, al-Durr al-Mansur, (Beirut: Dar al-Fikr, 1993), juz V, h. 160.

16 Al-Baidhawi, Tafsir al-Baidhawi, (Beirut: Dar al-Fikr, 1996 M / 1416 H), juz III, h. 416

17 Ibid.

18 Imam Muslim, Shahih Muslim, juz I, h. 39.

19 'Izz al-Din, al-Qawa'id al-Kubra, h. 34.

20 Ibid.

${ }^{21}$ Lihat Imam Muslim, Shahih Muslim, juz II, h. 697. Lihat juga Imam Bukhari, al-Jami' alShahih, juz. V. h. 2241.

22 'Izz al-Din, al-Qawa'id al-Kubra, h. 33.

${ }^{23}$ Lihat Imam Muslim, Shahih Muslim, juz III, h. 1548. Lihat juga Muhammad bin Hibban Ahmad Abu Hatim al-Tamimi al-Bisti (selanjutnya disebut Ibn Hibban), Shahih Ibn Hibban, (Beirut: Mu`assasah al-Risalah, 1414 H/1993 M), juz XIII, h. 199.

24 Muhammad Ab- Zahrah, Tarikh al-Mazahib al-Islamiyyah fi Tarikh al-Mazahib al-Fighiyyah, (Kairo: Dar al-Fikr al-'Arabi, tth), juz II, h. 82-86.

25 'Izz al-Din, al-Qawa'id al-Kubra, h. 38.

26 Ibid.

27 Lihat Imam Muslim, Shahih Muslim, juz. 4. h.2174. Lihat Juga Ibn hibban, Shahih Ibn Hibban, juz II, h. 492. 